telecharge.php?type=2\&file=/C_65_1/C65_1.html. Consulté le 14 février 2011.

2. Bussières JF, Lussier-Labelle F, Labelle B. Perspectives sur les achats groupés de médicaments en établissements de santé. Ruptures 2005; 10(1):21-38.

3. Règlement sur les contrats d'approvisionnement des organismes publics. c. C-65.1, r. 4. Publié au : www2.publicationsduquebec.gouv.qc.ca/ dynamicSearch/telecharge.php?type=3\&file=/C_65_1/C65_1R4.HTM. Consulté le 14 février 2011.

\section{Sophie Penfornis}

Interne en pharmacie

Assistante de recherche

Unité de recherche en pratique pharmaceutique

CHU Sainte-Justine

Montréal (Québec)

Jean-François Bussières, B. Pharm., M.Sc., FCSHP

Chef, Unité de recherche en pratique pharmaceutique

$\mathrm{CHU}$ Sainte-Justine

Montréal (Québec)

Sylvain Mathews, MD, FCRMCP

Chef, Département d'anesthésie

$\mathrm{CHU}$ Sainte-Justine

Montréal (Québec)

Jean-François Bussières est aussi chef du Département de pharmacie au CHU Sainte-Justine et professeur titulaire de clinique à la Faculté de pharmacie de l'Université de Montréal.

\section{Home Inotrope Program for Patients with End-Stage Heart Failure Awaiting Heart Transplant}

Many patients with advanced heart failure are admitted to hospital for inotrope support and may be considered for heart transplant. However, some patients with end-stage heart failure may be inotrope-dependent, and the wait time for a donor heart may be months. A prolonged hospital stay for inotrope therapy is expensive and is associated with substantial morbidity and lower quality of life. We therefore developed a home inotrope program in 2005 for inotrope-dependent patients with end-stage heart failure who were awaiting heart transplant. Here, we present a brief description of the program, along with outcome data for the first few years of operation.

Patients who had been admitted to our hospital (an urban tertiary care institution in British Columbia) for acute decompensated heart failure, for whom 2 attempts to wean from inotrope therapy had failed, and who had been receiving a stable dose of inotropes for 7 days were considered for the home inotrope program. In addition, the patients had to have met strict criteria for self-management of their heart failure. Only patients who were deemed to have end-stage heart failure, who were dependent on inotropes, and who were waiting for heart transplant were considered for the program. Home inotrope therapy was provided through a continuous IV line and ambulatory infusion pump. The dose of inotrope was not titrated once the patient was discharged home. Funding to cover the cost of inotropes was obtained from the British Columbia provincial government while the patient was at home, and patients were closely followed by the outpatient heart failure clinic and through home visits by nurses.

Between 2005 and 2009, a total of 6 patients were enrolled in the home inotrope program, and the clinical outcomes of these patients have now been reviewed and are presented here. The patients ranged in age from 26 to 63 years (median 51 years). Five of the patients were men, and all but one had non-ischemic heart failure. The median left ventricular ejection fraction was $17.5 \%$ (range $10 \%$ to $30 \%$ ). Patients received either dobutamine $5 \mu \mathrm{g} / \mathrm{kg}$ per minute or milrinone $0.5 \mu \mathrm{g} / \mathrm{kg}$ per minute by ambulatory infusion pump. All patients survived, and 5 of them eventually underwent heart transplant; the sixth patient was weaned off inotropes entirely, which made the planned transplant unnecessary. The median duration of home inotrope therapy was 27 days (range 2 to 118 days), which represents significant cost avoidance through the reduction in costs of hospital admission. Two of the 6 patients were readmitted during the course of their home inotrope therapy, but neither was readmitted because of arrhythmias secondary to the inotrope therapy.

The total cost of care in the cardiac ward was $\$ 1575$ per day, which included costs for nursing staff, equipment, supplies, and medications, and the total cost of home inotrope therapy was $\$ 183$ to $\$ 383$ per day (depending on the inotrope used), which included costs for home nursing visits, equipment, and supplies (data presented as mean costs of therapy over the period of the study, 2005 to 2009). The total cost of in-hospital inotrope therapy for these 6 patients would have been $\$ 381415$, whereas the total cost of their home inotrope therapy was $\$ 61585$. Therefore, the program saved a total of almost $\$ 320000$. Interestingly, the in-hospital cost of inotropes was lower $(\$ 20$ to $\$ 75$ per day) than the cost of outpatient therapy ( $\$ 100$ to $\$ 300$ per day), because of differences in contract drug prices for community and hospital pharmacies.

Centres in the United States have previously described the treatment of patients with end-stage heart failure with home inotrope therapy. ${ }^{1,2}$ However, the program described here is the first to document substantial cost savings to the hospital and is the first reported home inotrope program in Canada. The hospital pharmacist (D.C.) was integral to the development and maintenance of the home inotrope program, as he obtained funding from the provincial government to cover the cost of the inotropes to be administered at home and continues to participate in screening and enrolling patients into the program.

The home inotrope program at St Paul's Hospital in Vancouver has shown that selected patients with end-stage heart failure who are inotrope dependent can be treated at home while awaiting heart transplant. This program represents a financially attractive option for the hospital and is preferred by many patients. To our knowledge, this program is the only initiative of its kind in Canada and offers better care for the patient and is more economically sound for the hospital than admitting patients for indefinite inotrope therapy. Strong support from physicians and cardiac specialists and careful patient selection are critical to the success of this program. 


\section{References}

1. Dubrey SW, Banner N. Home inotrope treatment for intractable heart failure following heart transplantation. Heart 1999;82(2):248-251.

2. Jiménez J, Jara J, Bednar B, Bauerlein J, Mallon S. Long-term (> 8 weeks) home inotropic therapy as destination therapy in patients with advanced heart failure or as bridge to heart transplantation. Int $J$ Cardiol 2005;99(1):47-50.

Doson Chua, BSc(Pharm), PharmD, BCPS(AQ)

Clinical Pharmacy Specialist

Arvinder Buttar, BSN, RN

Patient Educator, Cardiac Surgery

Anemarie Kaan, MCN, RN, CCN(C)

Clinical Nurse Specialist

Holly Andrews, RN

Clinical Nurse Leader

Jennifer Kealy, RN, MSN, CCN(C)

Acute Heart Failure/Patient Educator

Stephanie Lam, MSW, RSW

Heart Function/Transplant Social Worker

St Paul's Hospital

Vancouver, British Columbia

\section{Effect of Albumin on Phenytoin Concentration: Are We Flogging a Dead Horse?}

Phenytoin is one of the oldest medications used to treat epilepsy. It is widely accepted that monitoring phenytoin therapy is complicated because of its nonlinear kinetics. It is also known that phenytoin is highly bound to albumin and that changes in albumin concentration can affect phenytoin concentration. ${ }^{1}$

However, clinical practice does not reflect this knowledge. An unpublished retrospective study performed at Ridge Meadows Hospital (a community hospital in Maple Ridge, British
Columbia, that operates under the umbrella of the Fraser Health Authority) showed that measurement of albumin level was not routinely ordered when measurement of phenytoin concentration was ordered. ${ }^{2}$ Since the study was performed, pharmacists in the Fraser Health Authority have been granted authority to order laboratory tests when required to make decisions about medication management. This is a step forward for pharmacists, in that we no longer need to remind physicians to order measurement of albumin levels. However, this "solution" may still result in delayed decision-making and/or unnecessary venipuncture for patients, as pharmacists may not realize the need to measure albumin until after the sample for measurement of phenytoin has been drawn. A more efficient and proactive solution would be for albumin level to be automatically measured whenever phenytoin concentration is determined.

Yes, phenytoin is an old drug. Yes, we know all about how albumin affects its pharmacokinetics. But we can still make changes to improve the current system, thus making clinical pharmacy more efficient and effective.

References

1. Patsalos PN, Berry DJ, Bourgeois BF, Cloyd JC, Glauser TA, Johannessen SI, et al. Antiepileptic drugs - best practice guidelines for therapeutic drug monitoring: a position paper by the subcommission on therapeutic drug monitoring, ILAE Commission on Therapeutic Strategies. Epilepsia 2008;49(7):1239-1276.

2. Co M. Impact of serum albumin on phenytoin level: twenty years later [lecture]. Fraser Health Research Week; 2008 Jun 17; Surrey (BC).

Michelle Co, BSc(Pharm)

Pharmacy

Ridge Meadows Hospital

Maple Ridge, British Columbia

Anita Lo, BSc(Pharm), PharmD

Pharmacy

Eagle Ridge Hospital

Port Moody, British Columbia

\begin{tabular}{lcc}
\multicolumn{3}{c}{ Advertisers } \\
\hline
\end{tabular}

